


\section{TECTONIC SETTING}

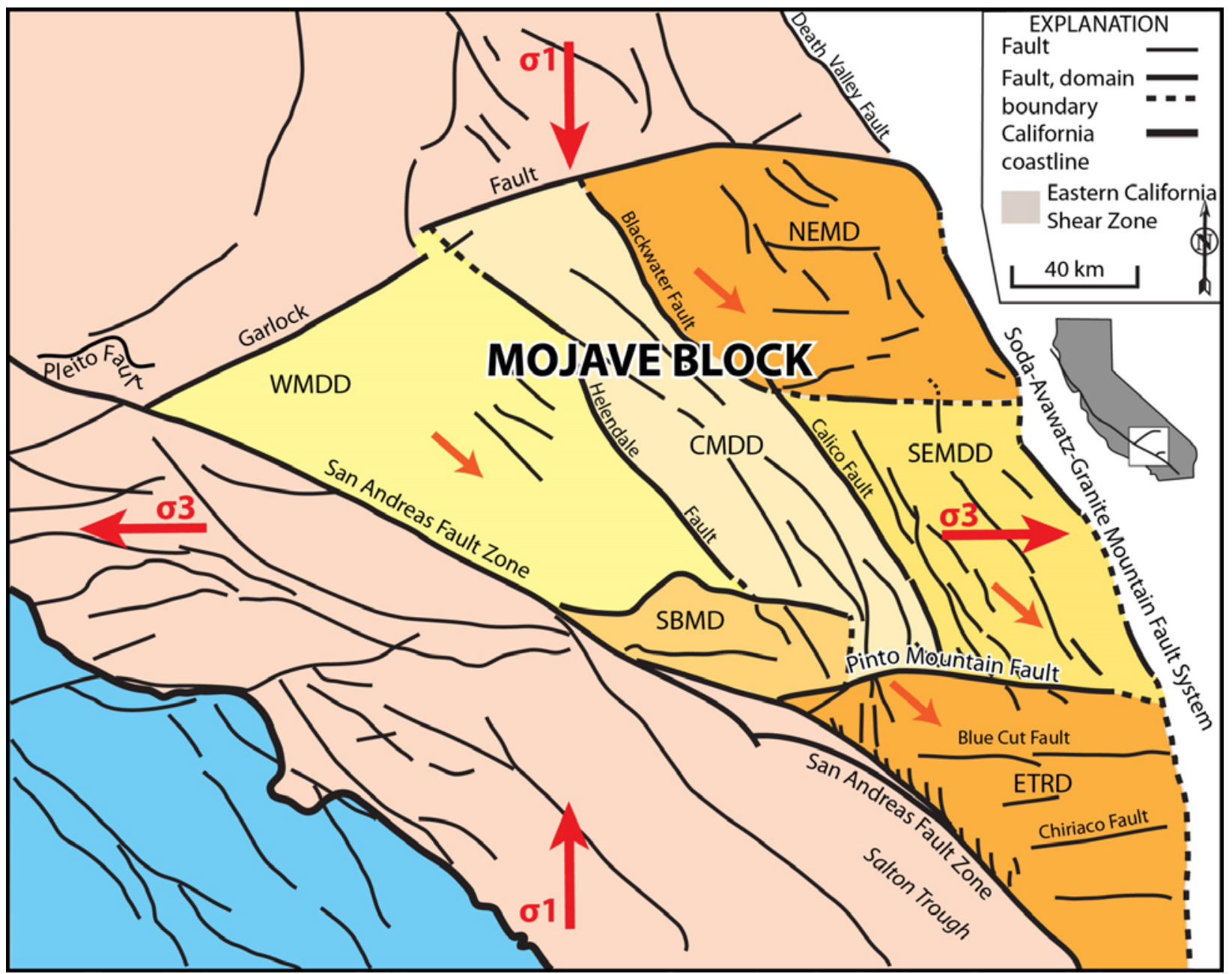




\section{GARLOCK FAULT}

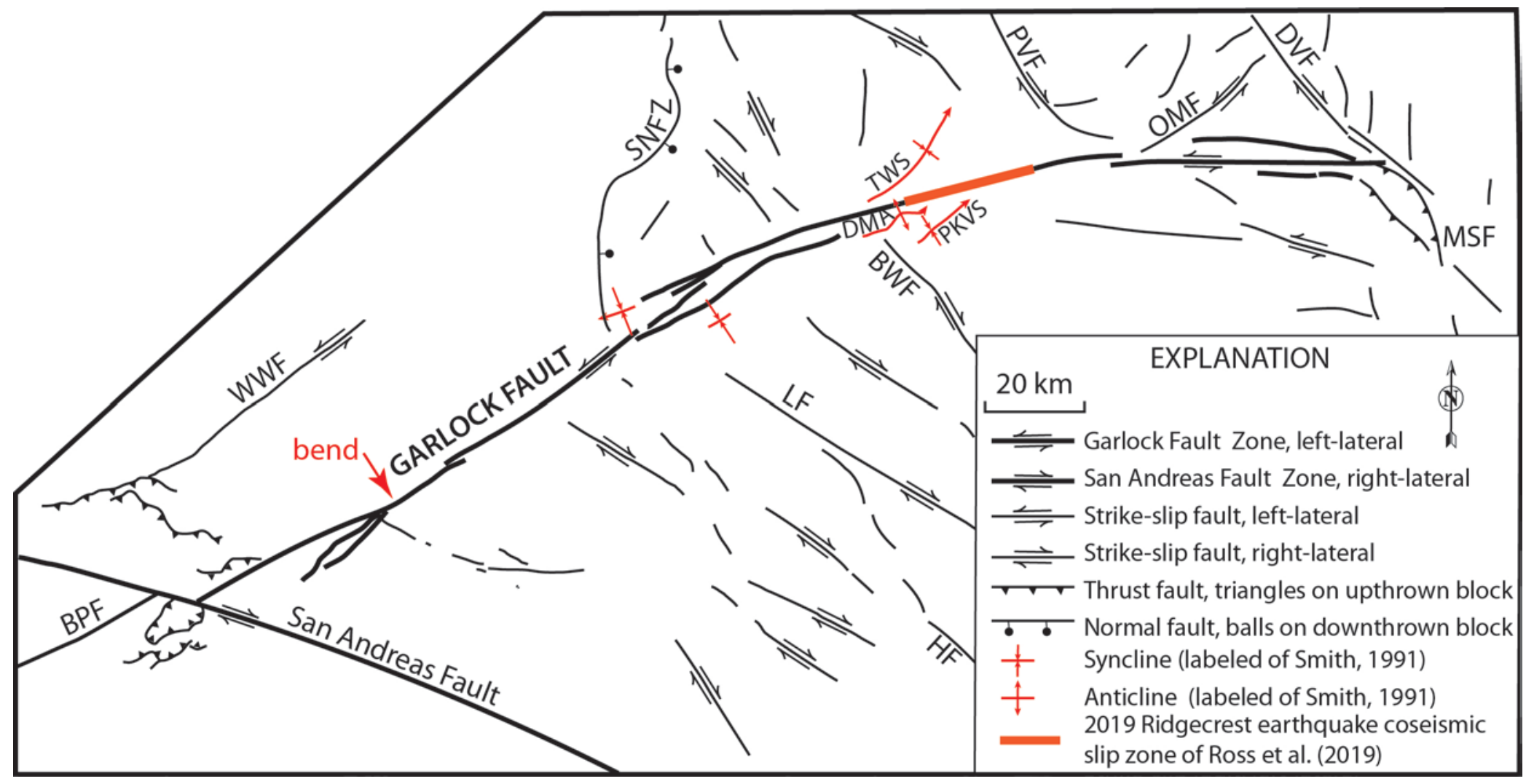




\section{PINTO MOUNTAIN FAULT}

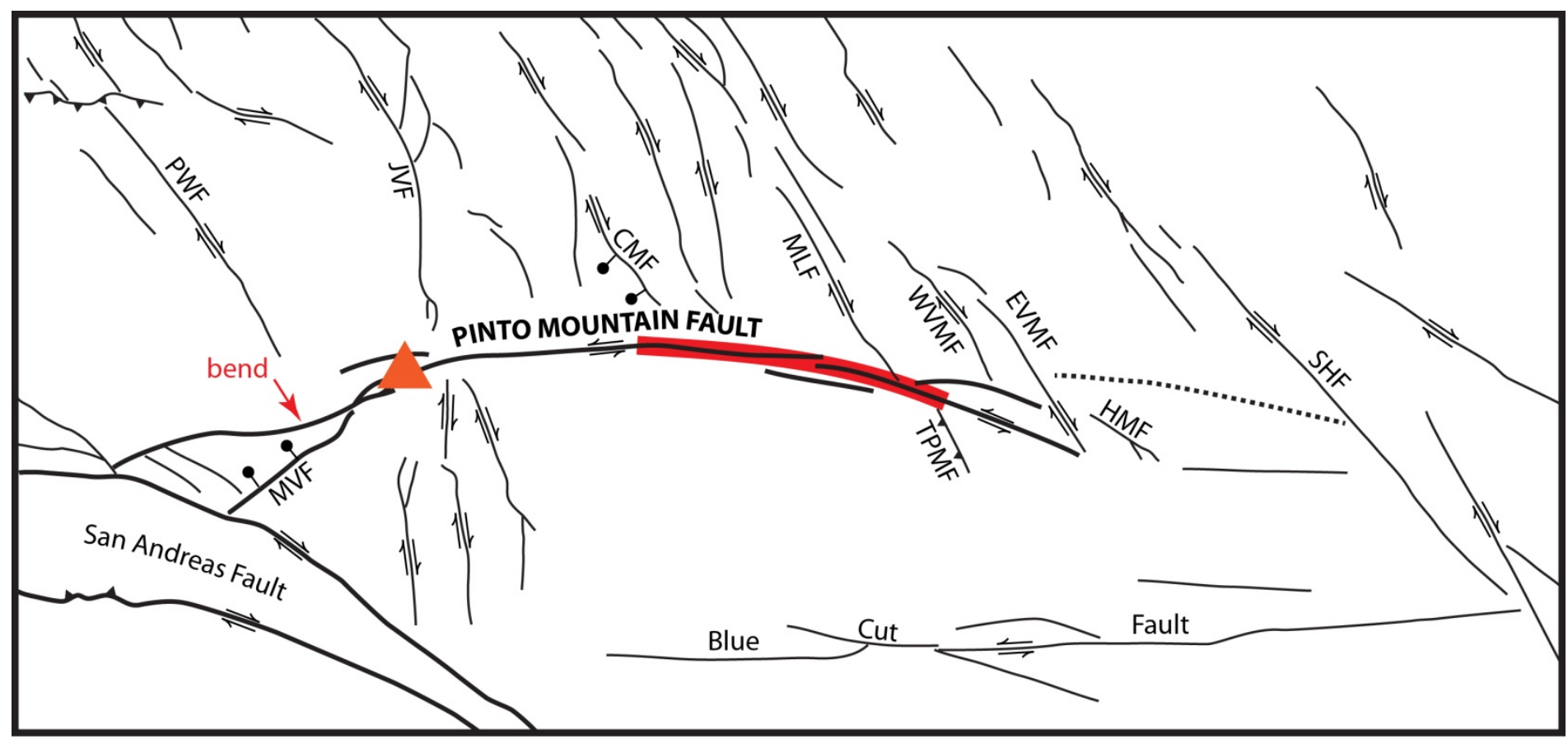

EXPLANATION

$\leftrightharpoons$ Pinto Mountain Fault Zone, left lateral, lines and balls denote local downdropped block

....... Abandoned Pinto Mountain Fault

$\rightleftharpoons$ San Andreas Fault Zone, right-lateral, triangles denote local upthrown block

$\leftrightharpoons$ Strike-slip fault, left-lateral

$\rightleftharpoons$ Strike-slip fault, right-lateral

-Thrust fault, barbs on upthrown block

$\Delta$ Landers earthquake coseismic slip fractures

$10 \mathrm{~km}$

Zone of contractional structures discussed in GSA talk 


\section{DISCUSSION}

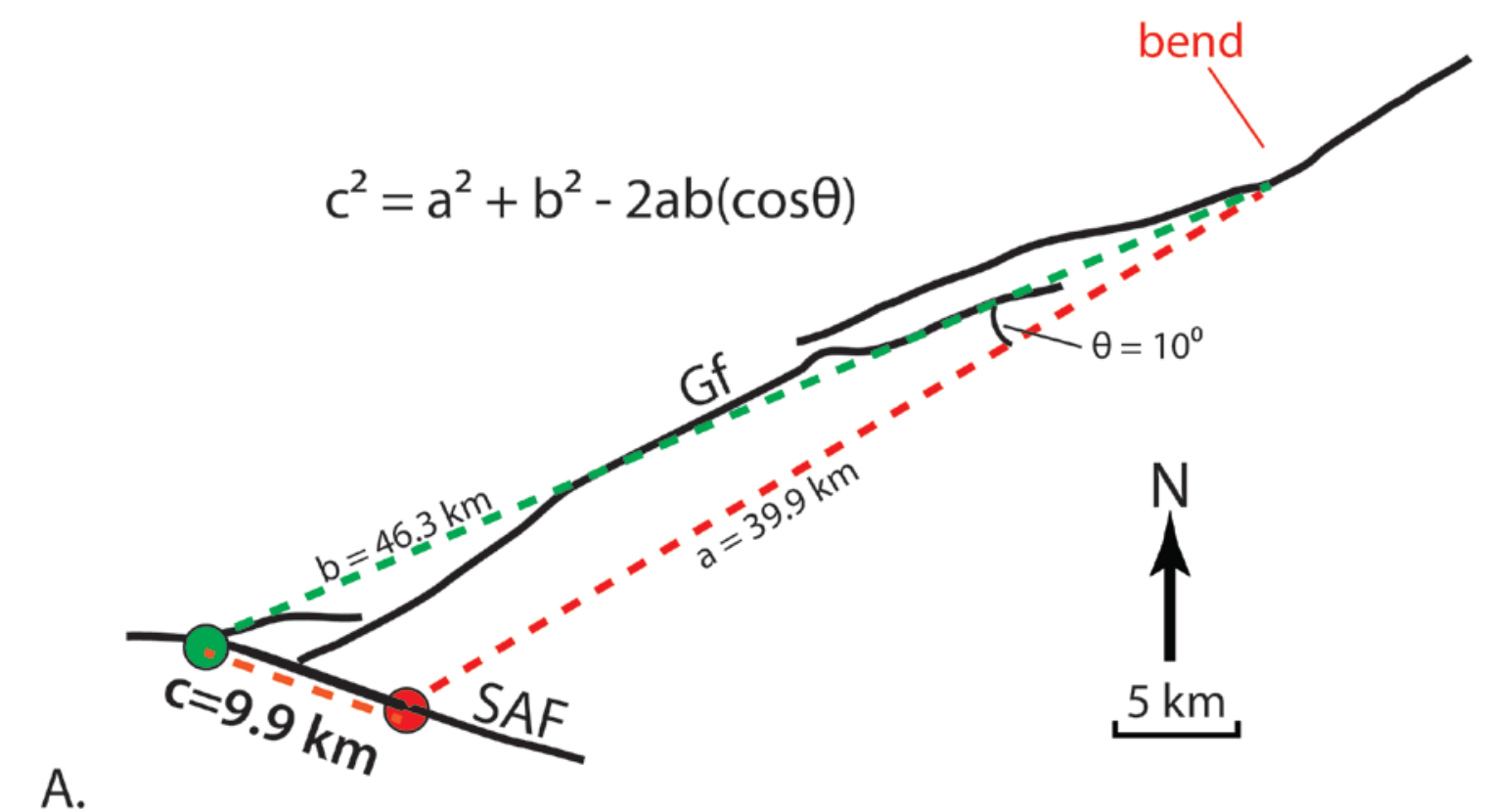

B.

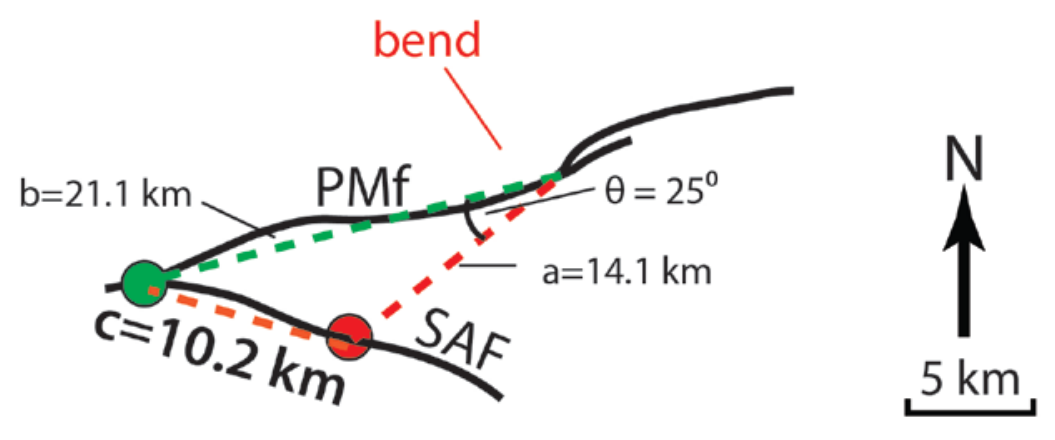




\section{DISCUSSION}

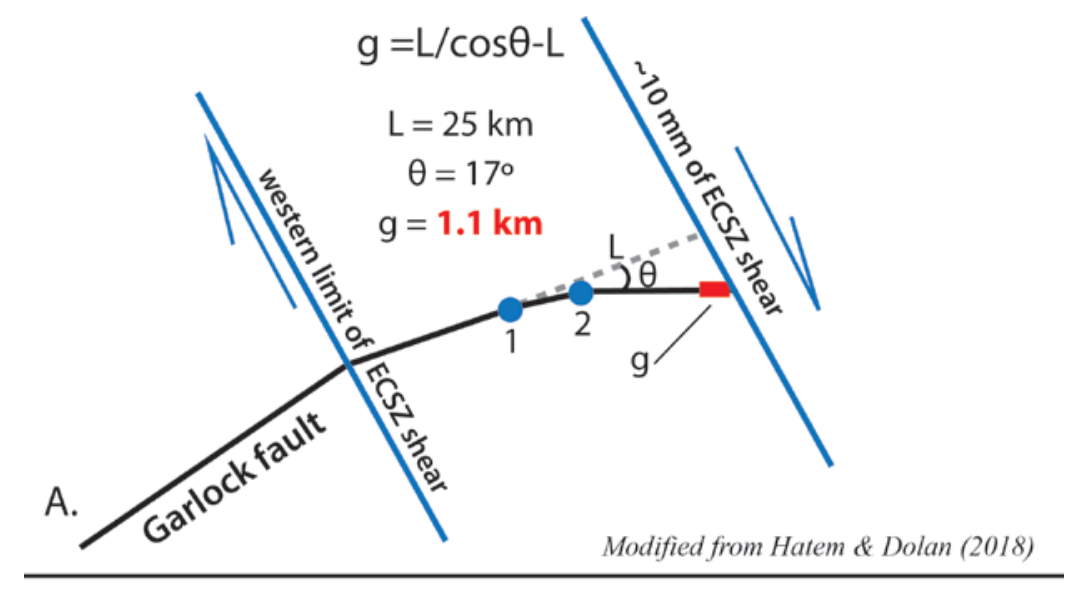

B.

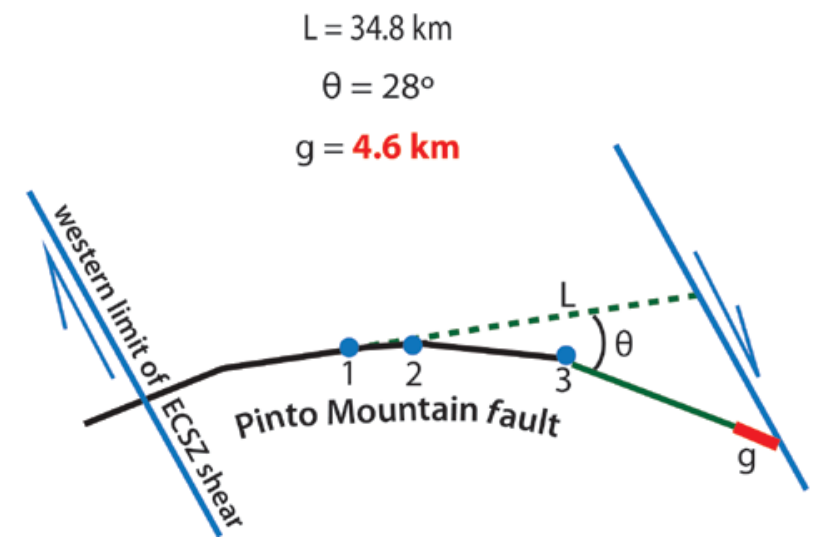




\section{DISCUSSION}

\section{Prefaulting Configuration of Mojave Block}

\section{Faults at 12 to $10 \mathrm{Ma}$}

$>$ Gf and PMf straight and oriented NE

$>$ Gf oriented $\mathrm{N} 60^{\circ} \mathrm{E}$ (Hatem \& Dolan, 2018)

$>$ PMf oriented $\mathrm{N} 44^{\circ} \mathrm{E}$

$>$ SAF oriented $\mathrm{N} 46^{\circ} \mathrm{W}$ (Dickinson, 1996)

$>$ Started out as conjugate (Hatem \& Dolan, 2018; Hill \& Dibblee, 1953)

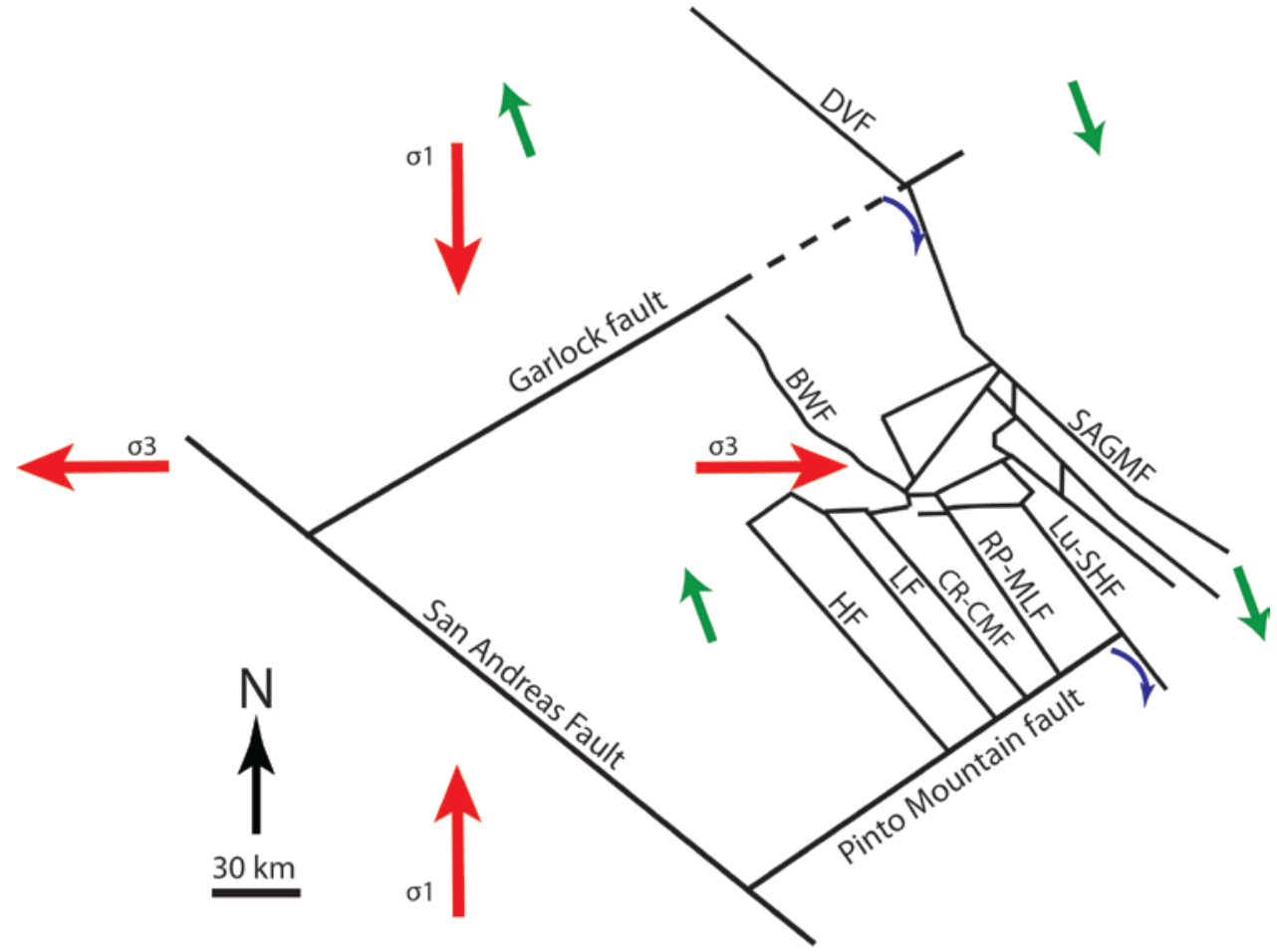




\section{DISCUSSION}

\section{Present-day Configuration of Mojave Block Faults}

$>\mathrm{SAF}$ deflected westward to present orientation

$>$ Westernmost and eastern segments of $\mathrm{Gf}$ and PMf rotated out of orientation favorable for conjugant slip

$>$ Right lateral shear across ECSZ oroclinally bent Gf and PMf

$>$ NEMD and ETRD rotated CW to accommodate bending

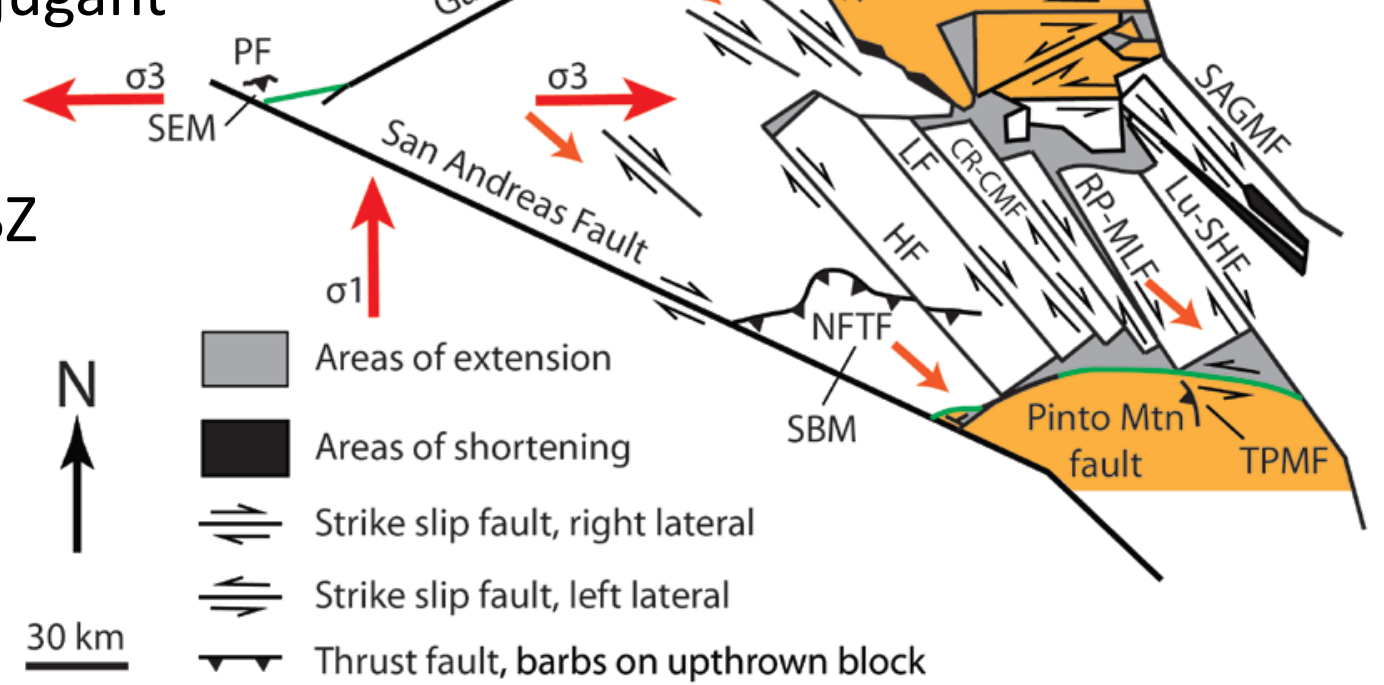




\section{DISCUSSION}

\section{Present-day Configuration of Mojave Block Faults}

$>\mathrm{N}-\mathrm{S}$ compression of $\mathrm{MB}$ results in uplift of SEMM and SBMD and forces a component of $\mathrm{MB}$ crust to "escape" to SSE

$>$ Right slip of SAF bends western parts of Gf and PMf and translates them $\sim 10 \mathrm{~km}$ to $\mathrm{NW}$

$>$ Transtension and transpression zones formed in response to block rotations

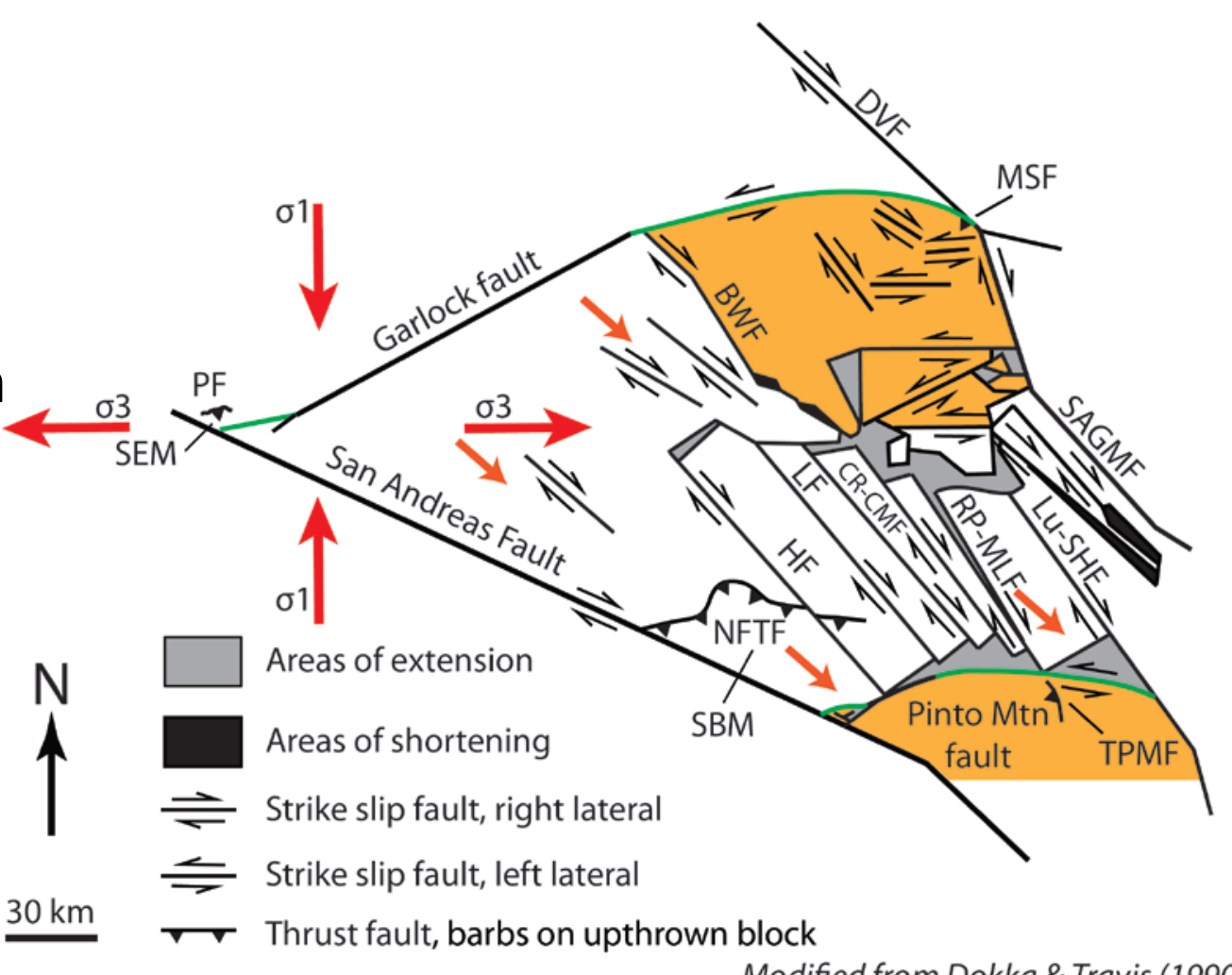


How are Gf and PMf kinematically linked?

1) SAF transfers strain to the Gf and PMf by...

a) conjugate slip

b) shifting the west ends of these faults right laterally

2) ECSZ transfers strain to Gf and PMf by...

a) oroclinal bending and block rotation

b) coseismic slip 


\section{REFERENCES}

\section{AVAILABLE UPON REQUEST}

\section{fhopson@sbcglobal.net}

Dixon, T.H. and Xie, S., 2018, A kinematic model for the evolution of the Eastern California Shear Zone and Garlock Fault, Mojave Desert, California: Earth and Planetary Science Letters, V. 494, p. 60-68.

Hatem, A. E., and Dolan, J. F., 2018, A model for the initiation, evolution, and controls on seismic behavior of the Garlock fault, California. Geochemistry, Geophysics, Geosystems, V. 19, p. 2166-2178. https://doi.org/10.1029/2017GC007349 